\title{
Montreal Cognitive Assessment in a 63- to 65-year-old Norwegian Cohort from the General Population: Data from the Akershus Cardiac Examination 1950 Study
}

\author{
Håkon Ihle-Hansen ${ }^{a, b}$ Thea Vigen ${ }^{b, c}$ Trygve Berge ${ }^{a, b} \quad$ Gunnar Einvik ${ }^{c}$ \\ Dag Aarsland d, e Ole Morten Rønning ${ }^{b, c}$ Bente Thommessen ${ }^{c}$ \\ Helge Røsjø ${ }^{b, c}$ Arnljot Tveita, b Hege Ihle-Hansen ${ }^{a}$ \\ a Department of Medical Research, Bærum Hospital, Vestre Viken Hospital Trust, Drammen, \\ Norway; ${ }^{b}$ Institute of Clinical Medicine, University of Oslo, Oslo, Norway; ${ }^{\text {c}}$ Division of \\ Medicine, Akershus University Hospital, Lørenskog, Norway; ${ }^{\mathrm{d}}$ Centre for Age-Related \\ Medicine, Stavanger University Hospital, Stavanger, Norway; ${ }^{~}$ Department of Old Age \\ Psychiatry, Institute of Psychiatry, Psychology \& Neuroscience, King's College London, \\ London, UK
}

\section{Keywords}

Cognitive screening test - Cognitive function - Montreal Cognitive Assessment - General population · Population-based study

\section{Abstract}

Aims: To investigate Montreal Cognitive Assessment (MoCA) test scores in a cohort aged 63-65 years from a general population in relation to the proposed cut-off score of 26 for mild cognitive impairment (MCI) and to explore the impact of education. Methods: MoCA scores were assessed in the Akershus Cardiac Examination 1950 Study, a cross-sectional cohort study of all men and women born in 1950 living in Akershus County, Norway. The participants were aged 63-65 at the time of data collection. Results: MoCA scores were available in 3,413 participants, of which $47 \%$ had higher education (>12 years). The mean MoCA score was 25.3 (95\% confidence interval [CI] 25.2-25.4), and 49\% had a score below the suggested cut-off of 26 points. Those with higher education had significantly higher scores (mean 26.2, 95\% CI $26.1-$ 26.3 vs. $24.4,95 \%$ CI $24.3-24.6, p<0.001$ ). Conclusions: Approximately $50 \%$ scored below the cut-off score of 26 points, suggesting that the cut-off score may have been set too high to distinguish normal cognitive function from MCI. Educational level had a significant impact on MoCA scores. 


\section{Introduction}

Cognitive decline and dementia due to Alzheimer disease (AD) as well as cerebrovascular disease are expected to become much more prevalent in the years to come [1], with increasing global socioeconomic impact [2]. According to the World Alzheimer Report from 2015, approximately 47 million people are living with dementia worldwide, and this number is estimated to nearly triple by 2050 [1]. In addition, vascular contribution to cognitive dysfunctions is suspected to increase. Since there is a lack of effective treatments for most dementia disorders, focus on early detection and prevention is demanding. Identification of individuals at risk for cognitive decline or with early stages of dementia for targeting known risk factors may preserve brain health [3]. Several cognitive assessment tools are available to screen for and identify cognitive impairment and dementia, but most of them are developed for identification of degenerative diseases at more advanced stages. Screening tools should include a comprehensive cognitive battery, but they may be challenging to use in order to differentiate between underlying pathologies. The well-known and probably most used cognitive screening test is the Mini-Mental State Examination (MMSE). This test is, however, of limited value in the early phase of mild cognitive impairment (MCI) and cognitive impairment of vascular aetiology [4, 5]. MMSE does not assess executive function, which is commonly affected in patient with vascular cognitive impairment (VCI) [6] and other cognitive disorders such as frontotemporal dementia and Lewy body dementia [7].

The Montreal Cognitive Assessment (MoCA) test is a brief measure of global cognitive function developed to detect early suspected cognitive deficits. The test is easy to administer, score, and interpret. It takes only a few minutes to perform and is suitable for use as a screening tool to identify patients with MCI and VCI in hospitals, in outpatient clinics, and by general practitioners [8-10]. The MoCA has been validated for people aged 55-85 years, is translated into several languages, and is extensively used in different parts of the world. In addition, MoCA has a high test-retest reliability and good internal consistency [8]. It measures different cognitive domains, including attention, concentration, executive functions, memory, language, visuoconstructive skills, abstract thinking, numeracy, and orientation. Compared to the MMSE, MoCA covers all the cognitive domains, including executive functioning, with better sensitivity and specificity in patients with MCI [8-11]. Further, MoCA shows comparable results to the MMSE in patients with mild AD $[8,12]$. The maximum score is 30 , and a score $\geq 26$ is interpreted as normal cognitive functioning. The publisher of MoCA has recommended a MoCA cut-off score of $<26$ for both MCI and AD [8]. Patients with MCI showed a mean score of 22.1 and patients with $\mathrm{AD}$ a mean score of 16.2 [8]. The MoCA score is proposed to be used for grading of the severity of diagnosed cognitive impairments, and a score $\geq 17$ may be used to distinguish MCI from dementia [13]. Further, the cut-off score of $<26$ was chosen for MCI due to an observed high sensitivity and specificity [8]. However, this cut-off score has been questioned [14]. A Cochrane analysis from 2015 found a high sensitivity of 94\%, but a low specificity of $60 \%$ or less for this cut-off score [14]. The authors concluded that there was insufficient evidence to give a clinical recommendation regarding a specific cut-off score [14]. Other studies have suggested that a lower cut-off score is more suitable. Therefore, normative data from large population-based studies are needed to decide the most appropriate cut-off score between normal functioning and cognitive impairment on the MoCA test $[15,16]$.

The MoCA test score is influenced by demographic data such as nationality, gender, age, and education [16-18]. Male gender and low education levels are associated with poorer score on the MoCA [17], the latter supposedly due to an educational component in cognitive testing. In the original work from Nasreddine et al. [8], a 1-point education compensation is suggested for those with $\leq 12$ years of education. In addition, symptoms of depression may influence cognitive performance $[19,20]$. The aim of the present study was to investigate 
MoCA test scores in a large middle-aged cohort from the general Norwegian population in relation to the recommended cut-off score, and to explore the impact of educational level and gender.

\section{Methods}

\section{Participants}

All participants were born in 1950 and were part of the Akershus Cardiac Examination (ACE) 1950 Study, a prospective, population-based cohort study of the cerebro- and cardiovascular health of all men and women born in 1950 in Akershus County, Norway. The study cohort is seen as a middle-aged population [21]. This particular age group was selected because the incidence of cardiovascular disease and cognitive impairment is still low but is expected to increase rapidly as the subjects grow older. The participants were examined at Akershus University Hospital (4,122 eligible subjects) and Bærum Hospital, Vestre Viken Hospital Trust (1,705 eligible), from June 2013 to May 2015.

\section{Assessments}

The design of the ACE 1950 Study is described in detail elsewhere [22]. Briefly, at the time of data collection, all participants were subjected to an interview regarding educational level, medical history (including self-reported cerebrovascular disease), and lifestyle, as well a clinical examination. Higher education was defined as $>12$ years of formal education. Depression was assessed using the 7-item depression subscale of the self-reporting questionnaire, the Hospital Anxiety and Depression Scale (HADS) [23]. Each item was scored from 0 to 4 , and according to previously established cut-off scores, the sum score was categorized into normal $(<8)$, possible clinical relevant depressive symptoms (8-10), and probable clinical relevant depressive symptoms $(>10)$.

The cognitive screening battery was chosen to assess all cognitive domains: (1) the 10-item wordlist test from the Consortium to Establish a Registry for AD (CERAD) neuropsychological battery [24], (2) the Trail Making Test A and B (TMT-A and -B) [25], and (3) the MoCA [8], performed in this order in all subjects. The brief neuropsychological assessments were administered by highly trained study nurses. The Norwegian 7.1 version of the MoCA test (available at www.mocatest.org) was used [26]. Participants with insufficient Norwegian language skills, anamnestic and/or known cognitive impairment/dementia based on hospital records, or other brain diseases were excluded from the analyses. The total sum score of MoCA is reported as raw score (defined as the score before using a 1-point education correction) or as education-corrected score. The MoCA results were evaluated in relation to the recommended cut-off score of 26 points [8]. A MoCA score $<17$ is suggested as a cut-off score to distinguish MCI from dementia [13], and was interpreted as a low test result in this study.

\section{Statistical Analysis}

Descriptive demographic and clinical measures are shown as mean \pm standard deviation (SD), or as numbers and frequencies. MoCA scores are given as mean and 95\% confidence interval (CI), and as median and interquartile range (IQR). An extra score point was added to the total MoCA score for subjects with $\leq 12$ years of formal education. The independent sample $t$ test was used to compare gender and education differences in the MoCA score as well as to compare the differences in MoCA score after excluding those with low test results. One-way ANOVA was used to compare the variance within the 3 HADS depression categories in relation to the MoCA score. A significance level was set at $p<0.05$. All analyses were performed using IBM SPSS Statistic 23 software. 
Table 1. Study population characteristics

\begin{tabular}{|c|c|}
\hline Data type & $\begin{array}{l}\text { With complete MoCA test } \\
(n=3,413)\end{array}$ \\
\hline \multicolumn{2}{|l|}{ Demographic data } \\
\hline Age, years & $63-65$ \\
\hline Male gender & 52.0 \\
\hline \multicolumn{2}{|l|}{ Cardiovascular risk factors } \\
\hline Hypertension & 58.3 \\
\hline Coronary heart disease & 7.0 \\
\hline Obesity (BMI >30) & 22.7 \\
\hline Stroke/TIA & 3.8 \\
\hline Daily smoking & 14.1 \\
\hline Diabetes mellitus & 9.9 \\
\hline Education $>12$ years & 47.4 \\
\hline Physical activity >30 min daily (all daily activity incl. work) & 84.7 \\
\hline Daily physical exercise & 17.2 \\
\hline \multicolumn{2}{|l|}{ HADS depression sum score } \\
\hline$<8$ & 94.5 \\
\hline $8-10$ & 3.9 \\
\hline$>10$ & 1.6 \\
\hline \multicolumn{2}{|l|}{ Cognitive performance } \\
\hline TMT-A, s & $38.0(37.5-38.4)$ \\
\hline$>60 \mathrm{~s}$ & 5.3 \\
\hline TMT-B, s & $96.4(94.8-98.1)$ \\
\hline$>188 \mathrm{~s}$ & 4.2 \\
\hline 10-item wordlist sum score & $22.1(22.0-22.2)$ \\
\hline$\leq 16$ & 5.8 \\
\hline 10-item wordlist delayed recall & $7.4(7.4-7.5)$ \\
\hline$\leq 5$ & 13.8 \\
\hline
\end{tabular}

Values are percentages unless otherwise indicated. Values in parentheses are $95 \%$ CI. Coronary heart disease, self-reported history of myocardial infarction, or cardiac bypass surgery or PCI with or without stent implantation; BMI, body mass index; TIA, transient ischemic attack; hypertension, mean blood pressure $>140 / 90 \mathrm{~mm} \mathrm{Hg}$ in sitting position after $10 \mathrm{~min}$ rest and/or use of antihypertensive drugs; diabetes, $\mathrm{HbA}_{1 \mathrm{c}}$ $\geq 6.5 \%$ and/or fasting plasma glucose $\geq 7.0 \mathrm{mmol} / \mathrm{L}$ and/or use of glucose-lowering medication; HADS, Hospital Anxiety and Depression Scale; TMT A and B, Trail Making Test A and B; 10-item wordlist list, test from The Consortium to Establish a Registry for Alzheimer's Disease (CERAD) neuropsychological battery.

\section{Results}

After inviting 5,827 participants, a total of 3,706 subjects were included in the ACE 1950 Study (attendance rate 64\%). The remaining 36\% were non-responders or declined to participate with no further explanations. After excluding 293 patients with missing data due to personal preference $(n=212)$, language problems $(n=74)$, or known cognitive impairment $(n=7), 3,413(92 \%)$ completed the MoCA test.

All included participants were born in 1950 and were 63-65 years of age at enrolment; 1,774 participants (52\%) were men, 1,615 (47\%) had higher education, 3,381 (99\%) were Caucasians, and 126 (4\%) had a history of self-reported cerebrovascular disease. Characteristics of the study population are presented in Table 1, and include measures of the other cognitive assessments and distributions of the HADS depression subscore. 
Fig. 1. Montreal Cognitive Assessment (MoCA) raw score distribution.

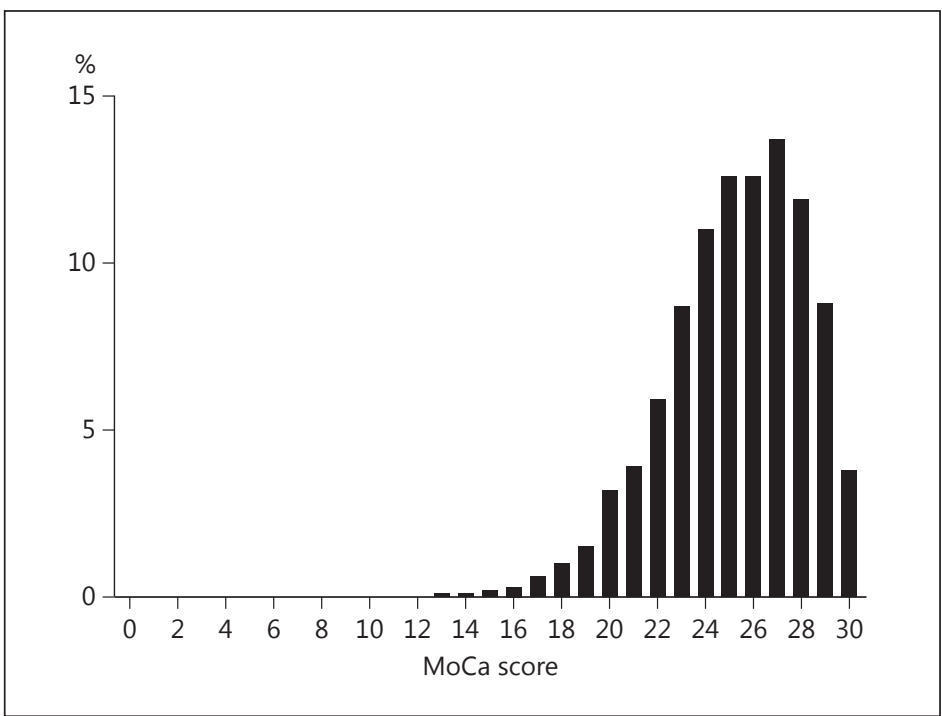

Table 2. MoCA score $( \pm \mathrm{SD})$ before and after a correction for education

\begin{tabular}{lll}
\hline & MoCA raw & Correction for education \\
\hline MoCA score & & \\
$\quad$ Total & $25.3 \pm 2.9$ & $25.8 \pm 2.8$ \\
Education $\leq 12$ years & $24.4 \pm 3.1$ & $25.4 \pm 3.0(+1$ point $)$ \\
$\quad$ Middle school, education $\leq 10$ years & $23.5 \pm 3.4$ & $25.4 \pm 3.3(+2$ points $)$ \\
$\quad$ High school, education $10-12$ years & $24.8 \pm 2.8$ & $25.8 \pm 2.8(+1$ point $)$ \\
Education $>12$ years & $26.2 \pm 2.5$ & $26.2 \pm 2.5$ \\
\hline
\end{tabular}

MoCA, Montreal Cognitive Assessment; SD, standard deviation.

The mean MoCA raw score was 25.3 (95\% CI 25.2-25.4). The overall distribution of MoCA scores is shown in Figure 1. The median MoCA score value was 26 (IQR 23-27). In total, $1,676(49 \%)$ of the participants from a general population had a score below the suggested cut-off score for MCI of 26 points. There was a significant gender difference, with women achieving a significantly higher score than men (mean $25.5,95 \%$ CI $25.4-25.6$ vs. $25.0,95 \%$ CI 24.9-25.2, $p<0.001$ ), independent of education level.

Excluding those with a MoCA score $<17(n=23)$ did not change the MoCA raw score significantly (mean 25.3, 95\% CI 25.3-25.4, median 26, IQR 24-27, $p=0.163$ ).

Educational level had a significant impact on the MoCA test results. Those with higher education scored significant higher compared to those with $\leq 12$ years of education (mean 26.2, 95\% CI 26.1-26.3, median 27 vs. mean 24.4, 95\% CI 24.3-24.6, median 25, $p<0.001$ ). After adding 1 point for individuals who had $\leq 12$ years as suggested in the test manual, the difference was partially equalized (mean 25.4 , 95\% CI 25.3-25.5, median 26). However, the MoCA score was still significantly higher among those with higher education $(p<0.001)$ (Table 2).

We found a significant difference between subgroups of those with $\leq 12$ years of education. Those with middle school ( $\leq 10$ years) or similar scored lower compared to those with high school or similar (10-12 years) (mean 23.5, 95\% CI 23.2-23.7, median 24 vs. mean 


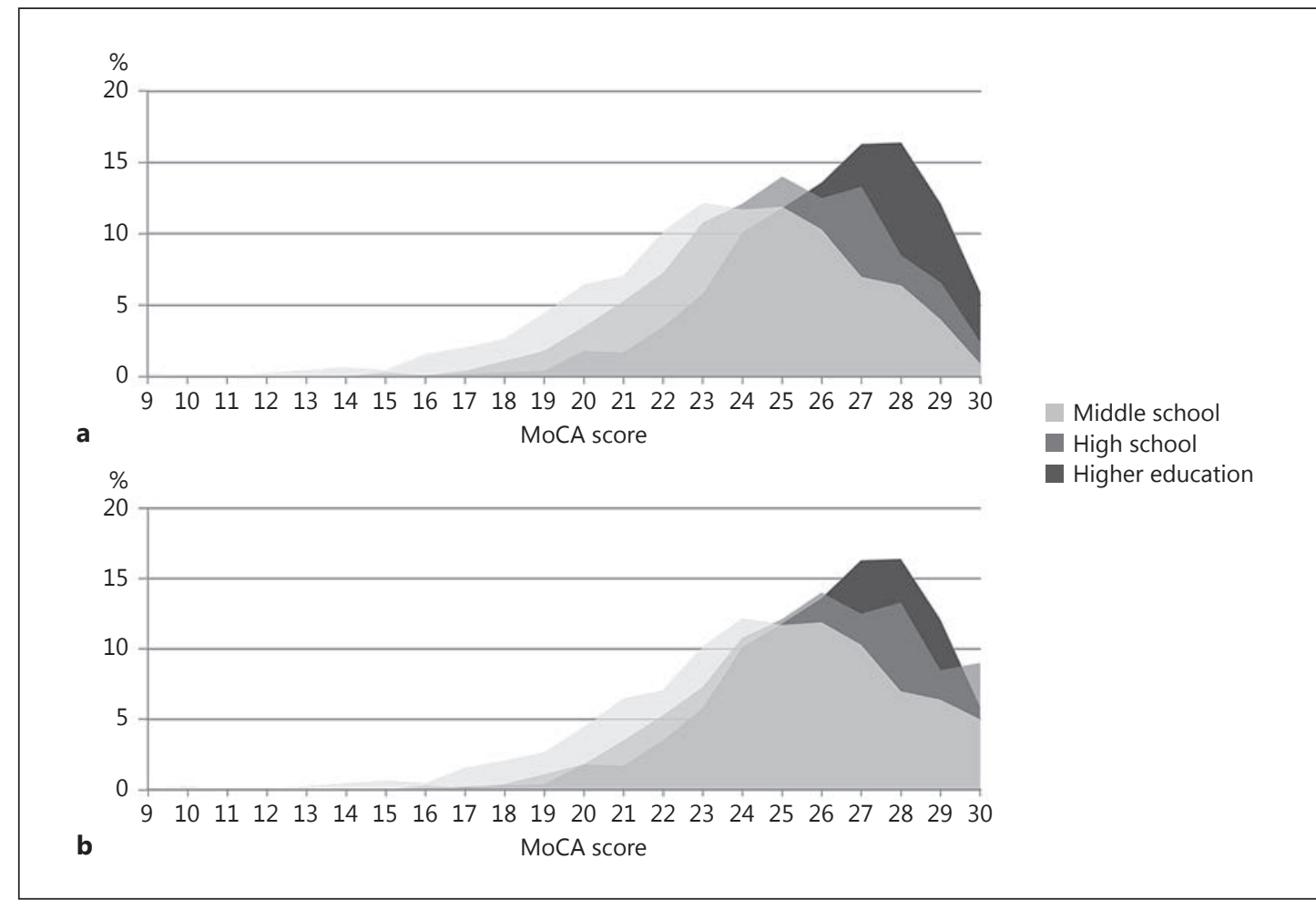

Fig. 2. Montreal Cognitive Assessment (MoCA) raw score distribution in relation to education (a) and after a 1-point education correction for $\leq 12$ years of education (b). Middle school, $\leq 10$ years of education; high school, 10-12 years of education; higher education, $>12$ years of education.

Table 3. MoCA raw score $( \pm S D)$ in relation to gender and education

\begin{tabular}{llcc}
\hline & Male & Female & $p$ value \\
\hline Middle school, education $\leq 10$ years & $23.0 \pm 3.4$ & $23.7 \pm 3.3$ & 0.01 \\
High school, education 10-12 years & $24.5 \pm 2.8$ & $25.2 \pm 2.7$ & $<0.001$ \\
Higher education & $25.9 \pm 2.5$ & $26.6 \pm 2.4$ & $<0.001$ \\
\hline
\end{tabular}

MoCA, Montreal Cognitive Assessment; SD, standard deviation.

24.8, 95\% CI 24.7-25.0, median 25, $p<0.001$ ). The distribution of the MoCA scores in relation to gender and educational level are shown in Table 3 and Figure 2, respectively. Educational level also influenced the TMT-A (mean 36.4, 95\% CI 35.7-37.0, median 34 vs. mean 39.3, 95\% CI 38.6-40.0, median 36, $p<0.001$ ), TMT-B (mean 86.1, 95\% CI 84.4-87.8, median 79 vs. mean 105.7, 95\% CI 103.1-108.4, median 91, $p<0.001$ ), and the 10-item wordlist (mean 23.0, 95\% CI 22.9-23.2, median 23 vs. mean 21.3 , 95\% CI 21.1-21.4, median $21, p<0.001$ ) test results.

The mean MoCA raw scores according to HADS depression categories were 25.2 (95\% CI 25.1-25.3, median 25), 25.6 (95\% CI 25.2-26.1, median 26) and 25.7 (95\% CI 24.9-26.5, median 27) in persons with a sum score $<8,8-10$, and $>10$, respectively. The difference between categories was not statistically significant $(p=0.107)$. 


\section{Discussion}

The mean MoCA raw score in a general population at the age of 63-65 years was 25.3, with a median of 26. Half of the population had a MoCA score below the suggested cut-off score of 26 points. After adding an extra point for persons with 12 years of education or less as suggested, those with higher education still had higher scores, and $42 \%$ scored below the cut-off score of 26 points. Participants with $\leq 12$ years of education showed great variation in the MoCA results. Further, there was a significant difference between $\leq 10$ years of education compared to $10-12$ years. In addition, women had significantly higher MoCA scores, while depressive symptoms did not influence the MoCA results. To our knowledge, this is the largest study that has reported the results of the MoCA test as a screening tool in a general population $[15,16]$.

Demographic variables seem to influence the MoCA score, with great variation in test results in different countries. Therefore, population-based data for MoCA scores are needed. The present study provides data from a middle-aged Norwegian cohort. The study cohort is considered rather healthy and well educated. Despite this, nearly 50\% scored below the suggested cut-off score of 26 points. When such a large proportion of the population scores below the recommended cut-off score, a MoCA cut-off score of 26 is probably not suitable to distinguish normal cognitive function from MCI when used as a screening tool in a general population. The suggested cut-off score of 26 was based on a sample of 90 healthy Canadian controls with a mean age of 73 years and mean education of 13 years. Using this cut-off score, the MoCA showed a sensitivity of $90 \%$ in MCI patients, a sensitivity of $100 \%$ in AD patients, and a specificity of $87 \%$. They concluded that a cut-off score of 26 reflected the best balance between specificity and sensitivity [8]. Another population-based study from Dallas, TX, USA, including 2,653 subjects with a mean age of 50.3 years, found a mean MoCA raw score of 23.4 [15]. Here, $66 \%$ scored below 26. In addition, the MoCA score correlated with education. These findings are in line with a recent study, where the MoCA score was evaluated in relation to age and education and $46 \%$ scored below 26 points [27]. Further, 1,977 subjects in Japan with a mean age of 73.6 years and mean education of 11.0 years showed a mean MoCA score of 21.8, where $83 \%$ scored below 26 points [28]. Finally, an Italian population with mean age of 57 years and mean education of 11.1 years showed a mean MoCA score of 22.0 [16]. Consistently in these population-based studies is a mean MoCA score $<26$ points, with a large proportion of the general population scoring below this cut-off score. These studies also show a clear association between education level and the MoCA score, which is confirmed by our study.

Usually, cognitive screening tests are performed in selected populations, i.e., groups with anamnestic cognitive complaints, organic disease, or suspected cognitive deficit. It is reasonable to assume that a selected population will differ from the general population in many ways, also in test results. However, several studies that include cases with cognitive impairment show the same trend as the population-based studies $[9,29,30]$. In general, the prerequisite for a good screening test is high sensitivity and specificity. The same is important in the diagnostic process in patients presenting with symptoms and signs of disease. This implies the need for a high sensitivity and a relatively high MoCA cut-off score, as outlined by Nasreddine et al. [8] in the examination for suspected cognitive impairment caused by dementia disorder. In a clinical setting, the initial screening should then be followed by a comprehensive test battery if the result is positive. However, dementia disorders are progressive diseases with no cure, and therefore, higher precision in screening for cognitive impairment should be preferred to avoid false-positive test results. Consequently, we recommend the use of a more clinically meaningful cut-off score with higher specificity. Our findings, as well as the similar studies listed above, suggest that the MoCA cut-off score of 26 may be set too high.

Our data show lower MoCA scores among those with $\leq 12$ years of education compared to those with higher education. This difference was partially equalized after adding a 1-point 
education correction, implicating that such a correction is meaningful. Further, our results revealed heterogeneity among participants with $\leq 12$ years of education, with significantly lower test scores among those with only middle school or similar. In this group, the difference was equalized if adding 2 education points (Table 2). The influence of education levels on cognitive test results is both logical and shown in several studies [18, 19, 28, 31]. Based on our findings, it seems reasonable to differentiate more between different levels of education and perhaps add 2 extra points for those with only middle school or similar.

There is conflicting evidence regarding the impact of gender on the MoCA test results [17, $18,28]$. We found a numerically small, yet statistically significant, gender difference in the MoCA score. Depression is an important differential diagnosis in cognitive impairments, and is also documented to influence cognitive screening test results [32], including MoCA in patients with cognitive impairments [20,33]. It is hypothesized that executive function, in particular, is affected by depressive symptoms, which also may affect global cognitive function scores. However, in our study, neither possible nor probable clinically relevant depressive symptoms were associated with lower MoCA score. This is in line with another general population-based study [34], and indicates that the influence of depression on global cognitive measures varies according to patient populations.

The main limitation of our study is that it was not designed to evaluate the cut-off score with sensitivity and specificity due to the lack of known diagnoses of MCI and dementia. Further, the MoCA test was conducted as the last of 4 tests during the study inclusion (after the 10-item wordlist test and TMT-A and -B), where the 10-item wordlist test may have interfered with the delay recall test and TMT-B with the trail making/visuoconstructive part of the MoCA test results. In addition, we used the official Norwegian version of the MoCA where traditional animals are absent. The strength of this study is the large number of participants and that the MoCA test was performed by highly trained investigators. An attendance rate of $64 \%$ is considered acceptable and in line with other Norwegian population-based studies [35-37]. An important aspect of this cohort is that the non-responders did not differ from the participants in terms of education [38]. Test results of the TMT-A and -B tests and the 10 -item wordlist test underline a normal cognitive function in the study cohort (Table 1). Demographically, the population is considered to comprise a cross-section of the Norwegian population, but with a slightly higher educational level [38].

\section{Conclusion}

This study provides data for the MoCA test in a middle-aged Norwegian communitybased population. Since the mean MoCA score was 25 and half of the population had a score of less than 26, our findings indicate that the cut-off score for cognitive impairment may be too high and must be interpreted with caution. Furthermore, we confirmed that education level and gender affect the MoCA score. Therefore, we suggest a correction based on different educational levels, adding 1 point in the group with 12 years and 2 points for those with only middle school education. There is a need for further studies exploring the impact of education on the MoCA test.

\section{Acknowledgements}

We appreciate the contribution of all our participants. We also thank our dedicated study staff at the Clinical Trial Unit, Division of Medicine, Akershus University Hospital, and the Department of Medical Research, Bærum Hospital, Vestre Viken Hospital Trust. We also acknowledge the contribution from other collaborating researchers in the ACE 1950 Study. 
Ihle-Hansen et al.: Montreal Cognitive Assessment in a General Population

\section{Statement of Ethics}

The study was approved by the Regional Committees for Medical and Health Research Ethics in Norway (Ref. No. 2011/1475). All participants signed a written informed consent before entering the study. The study is recorded at Clinicaltrials.gov (NCT01555411).

\section{Disclosure Statement}

All authors completed the ICMJE (International Committee of Medical Journal Editors) Conflict of Interest form and declare that PhD fellow Håkon Ihle-Hansen received a PhD scholarship from the nongovernmental patient organization Norwegian Health Association ("Nasjonalforeningen for Folkehelsen") for this study. No other support was received from any organization for the submitted work. There were no financial relationships with any organizations that might have an interest in the submitted work in the previous 3 years, and no other relationships or activities that could appear to have influenced the submitted work. The funding sources had no role in the study concept or design, the acquisition, analysis, or interpretation of data, or the preparation of the manuscript.

\section{References}

1 Wimo A, Guerchet M, Ali GC, Wu YT, Prina AM, Winblad B, Jonsson L, Liu Z, Prince M: The worldwide costs of dementia 2015 and comparisons with 2010. Alzheimers Dement 2017;13:1-7.

2 Prince M, Wimo A, Guerchet M, Ali G, Wu Y, Prina M: World Alzheimer Report 2015. The Global Impact of Dementia. An Analysis of Prevalence, Incidence, Cost and Trends. London, Alzheimer's Disease International, 2015.

-3 Ngandu T, Lehtisalo J, Solomon A, Levalahti E, Ahtiluoto S, Antikainen R, Backman L, Hanninen T, Jula A, Laatikainen T, Lindstrom J, Mangialasche F, Paajanen T, Pajala S, Peltonen M, Rauramaa R, Stigsdotter-Neely A, Strandberg T, Tuomilehto J, Soininen H, Kivipelto M: A 2-year multidomain intervention of diet, exercise, cognitive training, and vascular risk monitoring versus control to prevent cognitive decline in at-risk elderly people (FINGER): a randomized controlled trial. Lancet 2015;385:2255-2263.

4 Tang-Wai DF, Knopman DS, Geda YE, et al: Comparison of the short test of mental status and the mini-mental state examination in mild cognitive impairment. Arch Neurol 2003;60:1777-1781.

5 Dong Y, Sharma VK, Chan BP, Venketasubramanian N, Teoh HL, Seet RC, Tanicala S, Chan YH, Chen C: The Montreal Cognitive Assessment (MoCA) is superior to the Mini-Mental State Examination (MMSE) for the detection of vascular cognitive impairment after acute stroke. J Neurol Sci 2010;299:15-18.

6 Hachinski V, Iadecola C, Petersen RC, Breteler MM, Nyenhuis DL, Black SE, Powers WJ, DeCarli C, Merino JG, Kalaria RN, Vinters HV, Holtzman DM, Rosenberg GA, Wallin A, Dichgans M, Marler JR, Leblanc GG: National Institute of Neurological Disorders and Stroke-Canadian Stroke Network vascular cognitive impairment harmonization standards. Stroke 2006;37:2220-2241.

7 Johns EK, Phillips NA, Belleville S, Goupil D, Babins L, Kelner N, Ska B, Gilbert B, Inglis G, Panisset M, de Boysson $\mathrm{C}$, Chertkow H: Executive functions in frontotemporal dementia and Lewy body dementia. Neuropsychology 2009;23:765-777.

8 Nasreddine ZS, Phillips NA, Bédirian V, Charbonneau S, Whitehead V, Collin I, Cummings JL, Chertkow H: The Montreal Cognitive Assessment, MoCA: a brief screening tool for mild cognitive impairment. J Am Geriatr Soc 2005;53:695-699.

-9 Pendlebury ST, Mariz J, Bull L, Mehta Z, Rothwell PM: MoCA, ACE-R, and MMSE versus the National Institute of Neurological Disorders and Stroke-Canadian Stroke Network Vascular Cognitive Impairment Harmonization Standards Neuropsychological Battery after TIA and stroke. Stroke 2012;43:464-469.

10 Burton L, Tyson SF: Screening for cognitive impairment after stroke: a systematic review of psychometric properties and clinical utility. J Rehabil Med 2015;47:193-203.

11 Dong Y, Lee WY, Basri NA, Collinson SL, Merchant RA, Venketasubramanian N, Chen CL: The Montreal Cognitive Assessment is superior to the Mini-Mental State Examination in detecting patients at higher risk of dementia. Int Psychogeriatr 2012;24:1749-1755.

12 Smith T, Gildeh N, Holmes C: The Montreal Cognitive Assessment: validity and utility in a memory clinic setting. Can J Psychiatry 2007;52:329-332.

13 Trzepacz PT, Hochstetler H, Wang S, Walker B, Saykin AJ: Relationship between the Montreal Cognitive Assessment and Mini-Mental State Examination for assessment of mild cognitive impairment in older adults. BMC Geriatr 2015;15:107.

-14 Davis DH, Creavin ST, Yip JL, Noel-Storr AH, Brayne C, Cullum S: Montreal Cognitive Assessment for the diagnosis of Alzheimer's disease and other dementias. Cochrane Database Syst Rev 2015;10:Cd010775. 
15 Rossetti HC, Lacritz LH, Cullum CM, Weiner MF: Normative data for the Montreal Cognitive Assessment (MoCA) in a population-based sample. Neurology 2011;77:1272-1275.

-16 Santangelo G, Siciliano M, Pedone R, Vitale C, Falco F, Bisogno R, Siano P, Barone P, Grossi D, Santangelo F, Trojano L: Normative data for the Montreal Cognitive Assessment in an Italian population sample. Neurol Sci 2015;36:585-591.

-17 Larouche E, Tremblay MP, Potvin O, Laforest S, Bergeron D, Laforce R, Monetta L, Boucher L, Tremblay P, Belleville S, Lorrain D, Gagnon JF, Gosselin N, Castellano CA, Cunnane SC, Macoir J, Hudon C: Normative data for the Montreal Cognitive Assessment in middle-aged and elderly Quebec-French people. Arch Clin Neuropsychol 2016;31:819-826.

-18 Kopecek M, Stepankova H, Lukavsky J, Ripova D, Nikolai T, Bezdicek O: Montreal Cognitive Assessment (MoCA): normative data for old and very old Czech adults. Appl Neuropsychol Adult 2017;24:23-29.

19 de Azeredo Passos VM, Giatti L, Bensenor I, Tiemeier H, Ikram MA, de Figueiredo RC, Chor D, Schmidt MI, Barreto SM: Education plays a greater role than age in cognitive test performance among participants of the Brazilian Longitudinal Study of Adult Health (ELSA-Brasil). BMC Neurol 2015;15:191.

-20 Blair M, Coleman K, Jesso S, Desbeaumes Jodoin V, Smolewska K, Warriner E, Finger E, Pasternak SH: Depressive symptoms negatively impact Montreal Cognitive Assessment performance: a memory clinic experience. Can J Neurol Sci 2016;43:513-517.

21 Oxford University Press: Oxford Dictionaries: definition of middle age in English. 2017. https://www. en.oxforddictionaries.com/definition/us/middle_age (accessed January 26, 2017)

-22 Berge T, Vigen T, Pervez MO, Ihle-Hansen H, Lyngbakken MN, Omland T, Smith P, Steine K, Rosjo H, Tveit A: Heart and brain interactions - the Akershus Cardiac Examination (ACE) 1950 Study design. Scand Cardiovasc J 2015;49:308-315.

23 Zigmond AS, Snaith RP: The Hospital Anxiety and Depression Scale. Acta Psychiatr Scand 1983;67:361-370.

-24 Mirra SS, Heyman A, McKeel D, Sumi S, Crain B, Brownlee L, Vogel F, Hughes J, Van Belle G, Berg L: The Consortium to Establish a Registry for Alzheimer's Disease (CERAD). Part II. Standardization of the neuropathologic assessment of Alzheimer's disease. Neurology 1991;41:479-486.

25 AITB (Army Individual Test Battery): Manual of Directions and Scoring. Washington, War Department, Adjutant General's Office, 1944.

26 Nasreddine Z: Montreal Cognitive Assessment (MoCA) 7.1 Norwegian version. http://www.mocatest. org/wp-content/uploads/2015/tests-instructions/MoCA-Instructions-Norwegian.pdf (accessed January 7, 2017).

-27 Malek-Ahmadi M, Powell JJ, Belden CM, O’Connor K, Evans L, Coon DW, Nieri W: Age- and education-adjusted normative data for the Montreal Cognitive Assessment (MoCA) in older adults age 70-99. Neuropsychol Dev Cogn B Aging Neuropsychol Cogn 2015;22:755-761.

-28 Narazaki K, Nofuji Y, Honda T, Matsuo E, Yonemoto K, Kumagai S: Normative data for the Montreal Cognitive Assessment in a Japanese community-dwelling older population. Neuroepidemiology 2013;40:23-29.

29 Godefroy O, Fickl A, Roussel M, Auribault C, Bugnicourt JM, Lamy C, Canaple S, Petitnicolas G: Is the Montreal Cognitive Assessment superior to the Mini-Mental State Examination to detect poststroke cognitive impairment? A study with neuropsychological evaluation. Stroke 2011;42:1712-1716.

-30 O'Caoimh R, Timmons S, Molloy DW: Screening for mild cognitive impairment: comparison of "MCI specific" screening instruments. J Alzheimers Dis 2016;51:619-629.

-31 Ganguli M, Snitz BE, Lee CW, Vanderbilt J, Saxton JA, Chang CC: Age and education effects and norms on a cognitive test battery from a population-based cohort: the Monongahela-Youghiogheny Healthy Aging Team. Aging Ment Health 2010;14:100-107.

-32 Ganguli M, Du Y, Dodge HH, Ratcliff GG, Chang CC: Depressive symptoms and cognitive decline in late life: a prospective epidemiological study. Arch Gen Psychiatry 2006;63:153-160.

-33 Yatawara C, Lim L, Chander R, Zhou J, Kandiah N: Depressive symptoms influence global cognitive impairment indirectly by reducing memory and executive function in patients with mild cognitive impairment. J Neurol Neurosurg Psychiatry 2016;87:1375-1383.

-34 Freitas S, Simoes MR, Alves L, Santana I: Montreal Cognitive Assessment: influence of sociodemographic and health variables. Arch Clin Neuropsychol 2012;27:165-175.

-35 Refsum H, Nurk E, Smith AD, Ueland PM, Gjesdal CG, Bjelland I, Tverdal A, Tell GS, Nygard O, Vollset SE: The Hordaland Homocysteine Study: a community-based study of homocysteine, its determinants, and associations with disease. J Nutr 2006;136(suppl 6):1731s-1740s.

-36 Krokstad S, Langhammer A, Hveem K, Holmen TL, Midthjell K, Stene TR, Bratberg G, Heggland J, Holmen J: Cohort profile: the HUNT Study, Norway. Int J Epidemiol 2013;42:968-977.

37 The Artic University of Norway (UiT): The Sixth Tromsø Study 2007-2008. The sixth survey of the Tromsø Study (Tromsø 6)]. Available from: https://en.uit.no/prosjekter/prosjekt?p_document_id=104991 (accessed December 8, 2016).

38 Statistics Norway (SSB): SSB Educational level in Norway. 2016. https://www.ssb.no/statistikkbanken/ selectvarval/Define.asp? subjectcode $=\&$ ProductId $=\&$ MainTable $=$ Utdanningsniv0 $\&$ nvl $=\& P$ Language $=$ $0 \&$ nyTmpVar=true $\&$ CMSSubjectArea $=u$ tdanning \&KortNavnWeb $=u$ tniv $\&$ StatVariant $=\&$ checked $=$ true (accessed December 8, 2016). 